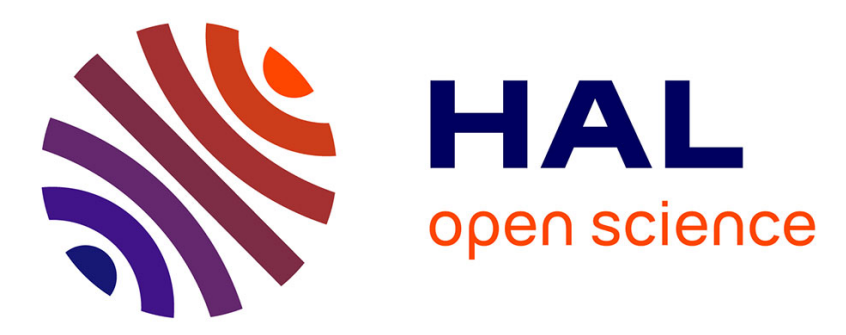

\title{
Quantity-quality management of a groundwater resource by a water agency
}

K. Erdlenbruch, M. Tidball, G. Zaccour

\section{To cite this version:}

K. Erdlenbruch, M. Tidball, G. Zaccour. Quantity-quality management of a groundwater resource by a water agency. Environmental Science and Policy, 2014, 44, p. 201 - p. 214. 10.1016/j.envsci.2014.08.002 . hal-01068019

\section{HAL Id: hal-01068019 https://hal.science/hal-01068019}

Submitted on 24 Sep 2014

HAL is a multi-disciplinary open access archive for the deposit and dissemination of scientific research documents, whether they are published or not. The documents may come from teaching and research institutions in France or abroad, or from public or private research centers.
L'archive ouverte pluridisciplinaire HAL, est destinée au dépôt et à la diffusion de documents scientifiques de niveau recherche, publiés ou non, émanant des établissements d'enseignement et de recherche français ou étrangers, des laboratoires publics ou privés. 


\title{
Quantity-Quality Management of a Groundwater Resource by a Water Agency
}

\author{
Katrin Erdlenbruch* \\ Irstea, UMR G-EAU, Montpellier, France \\ Mabel Tidball \\ INRA, UMR Lameta, Montpellier, France \\ Georges Zaccour \\ Chair in Game Theory and Management, GERAD, HEC Montréal, Canada ${ }^{\dagger}$
}

Version: $28 / 07 / 2014$

\begin{abstract}
This paper constructs a dynamic game model to address the following groundwater management problem, where quantity and quality of the water are taken into account. A group of farmers overexploits a groundwater stock and causes excessive pollution. A water agency wishes to regulate the farmers' activity, in order to reach a minimum level of quantity and quality but is subject to a budget constraint and can only use regulatory policies that do not vary over time. The model takes into account the strategic interaction between farmers and the hierarchical relationship between the water agency and the farmers. Regulated and laisser-faire scenarios are compared. Results consist in a set of conditions under which constant policies can bring the groundwater resource back to the desired states. In an example, it is shown how this decision making tool could help define environmental tax policies.
\end{abstract}

JEL classification: H23, Q15, Q25.

Key words: groundwater management, quantity-quality management, dynamic game, Stackelberg game, socio-ecological system.

*Irstea, UMR G-EAU, 361 rue Jean François Breton, 34196 Montpellier cedex 5, France. Tel: +33467046387. E-mail: katrin.erdlenbruch@irstea.fr (Corresponding author).

${ }^{\dagger}$ K. Erdlenbruch and M. Tidball acknowledge financial support from the French National Research Agency through grant ANR-08-JCJC-0074-01. Georges Zaccour acknowledges support of SSHRC and NSERC, Canada. 


\section{Introduction}

The management of groundwater is a typical common-pool renewable resource problem where several users have to share the same resource stock. Not only the volume but also the quality of the water is a common feature of the stock. Therefore, any attempt to regulate the use of water has to tackle externalities ${ }^{1}$ related to both quantity and quality.

A significant literature has analyzed the quantitative management of water resources. While Gisser and Sanchez (1980) [9] argued that policy intervention was not justified (see Koundouri 2004 [12] for a survey), the consideration of more complicated resource problems and other externalities has shown that public intervention may be necessary, e.g., when several resources are interlinked (Zeitouni and Dinar 1997 [24]), when groundwater has a buffer value against surface water scarcity (Provencher and Burt 1993 [17]), when shocks on the recharge level occur (De Frutos Cachorro et al. 2014 [5]), or when quality is taken into account (Esteban and Albiac 2011 [8], Roseta Palma 2003 [19]).

Concerning water quality, the problem of nitrate pollution to inland resources has become a major issue in many places. ${ }^{2}$ On the one hand, the intensification of agriculture has increased this type of pollution; on the other hand, quality norms have become more stringent because groundwater resources are often used for drinking water. Many frameworks have been used to determine optimal water and nitrogen use in agricultural production, including dynamic models (e.g., Knapp and Schwabe, 2006 [11]; Xepapadeas 1992 [22]; Yadav 1997 [23]). Yet, as Koundouri 2004 [12] points out, these models "generally avoid the relationship between contamination of groundwater and water-use decisions. The assessment of how much groundwater should be pumped is absent from these models."

The first work that brings together these aspects in a dynamic setting is by Roseta Palma (2002 [18] and 2003 [19]). Roseta Palma models explicitly the link between water quantity and water quality distinguishing two effects: the stock dilution effect, which describes the beneficial impact of water volume on water quality, and the contaminating vector effect in which contaminants infiltrate more easily into the soil when transported by irrigation water. She also shows that optimal regulation should address both quantity and quality externalities.

This paper extends the work by Roseta Palma (2002, 2003), constructing a model in which the water users react to the policies of a water agency. The model describes a group of irrigating farmers using the same groundwater resource. The fertilizer used by the farmers leaches into the groundwater and causes nitrate pollution, which is mitigated by the stock dilution effect and the natural decay rate of the contaminant. Farmers optimize their individual payoffs without considering the impact of their decisions on the stock of water and its quality. To ensure sustainable use of the resource, a water agency is in charge of regulating the quantity and quality of the groundwater. Regulation takes the form of taxes on water withdrawal and use of fertilizers and of a subsidy program for the use of nitrogen-fixing plants. ${ }^{3}$ It is assumed that the regulator commits to constant policies over one fiscal year. ${ }^{4}$

\footnotetext{
${ }^{1} \mathrm{~A}$ negative (positive) externality is an action that imposes a negative (positive) effect on a third party without any compensation being considered.

${ }^{2}$ Another major issue addressed in the literature is the problem of saltwater intrusion in coastal aquifers (see, e.g., Cummings 1971 [4]; Dinar and Xepapadeas 1998 [6]; Knapp and Baerenklau 2006 [10]; Moreaux and Reynaud 2006 [16]; Tsur and Zemel 2004 [21]; Zeitouni and Dinar 1997 [24]).

${ }^{3}$ This is the green manure concept: some plants including white mustard (Sinapis alba), vetches (Vicia), phacelia or rapeseed (Brasica napus) are able to fix nitrogen in the field. They are planted after the main harvest, in the fall and plowed in winter.

${ }^{4}$ Many articles consider dynamic taxation as a tool for policy intervention (e.g. Burness and Brill 2001 [1] or Roseta Palma 2003 [19]). However, dynamic taxation requires that the regulator chooses an optimal policy
} 
The model assumptions concerning the regulatory context are inspired by the current situation in France. In each major water basin, a water agency is in charge of the water policy and can levy taxes and provide subsidies. The water agency faces different constraints. First, it is supposed to reach the goals of several European Directives (for instance, Directive 2000/60/EC, Directive 2006/118/EC, Directive 91/676/EEC). Next, it is endowed with a budget at the start of the planning horizon and must balance its books at the end of the fiscal exercise. There is a water withdrawal tax (but it is considered to be too low to be an incentive) and several taxes on polluting inputs (but none apply to nitrate (CAS 2011 [2])). All taxes are constant over the year. Finally, subsidies were in place to favor the use of plants containing nitrogen-fixing symbiotic bacteria (but they are not used anymore). ${ }^{5}$ It is thus interesting to set up a model in which these different constraints and tax and subsidy policies can be introduced in order to evaluate their amount.

The above model assumptions lead to the study of a non-standard dynamic game with three state variables and multiple constraints. The model takes into account the interaction between the farmers and the relation between farmers and the regulatory agency. Results of two scenarios are contrasted: the laisser-faire scenario, in which the use of water is not regulated and which is used as a benchmark, and the scenario where the water agency regulates farming activity. The regulation scenario is constructed as a Stackelberg game, where the water agency is the leader and the farmers are the followers. The analysis shows that setting realistic tax policies is not a trivial task for a water agency. The model presented can be considered as a decision making tool which might help water agencies to define the level of constant input taxes.

The paper is structured as follows. In section 2, the model, a simplified agro-economic model including a groundwater resource, is described. In section 3, the Stackelberg game is presented and its solution analyzed. In section 4, optimal taxation policies are computed in different examples. The last section contains the conclusion and some suggestions for future research.

\section{The Model}

\subsection{The Farmers}

A group of $N$ farmers is considered, growing a single agricultural product on land located above the same groundwater resource. Time $t$ is continuous and the planning period is $[0, T]$. The agricultural production $y_{i}(t)$, of farmer $i=1, \ldots N$, at time $t \in[0, T]$, depends on two inputs, the quantity of fertilizer spread on cultivated land, $f_{i}(t)$, and the volume of irrigation water, $w_{i}(t)$, that each farmer pumps from the groundwater resource. The production function, $y_{i}\left(w_{i}(t), f_{i}(t)\right)$ has the following properties:

$$
\frac{\partial y_{i}}{\partial w_{i}} \geq 0, \frac{\partial y_{i}}{\partial f_{i}} \geq 0, \frac{\partial^{2} y_{i}}{\partial w_{i}^{2}} \leq 0, \frac{\partial^{2} y_{i}}{\partial f_{i}^{2}} \leq 0, \frac{\partial^{2} y_{i}}{\partial w_{i} \partial f_{i}} \geq 0
$$

In particular, following Roseta Palma (2003) [19], a functional form can be given:

$$
y_{i}(t)=A w_{i}(t) f_{i}(t)+B w_{i}(t)+E f_{i}(t)-\frac{K}{2}\left(f_{i}(t)\right)^{2}-\frac{M}{2}\left(w_{i}(t)\right)^{2}+G,
$$

where $A, B, E, K, M$ and $G$ are non- negative parameters.

\footnotetext{
that changes constantly. Moreover, the regulator would need to be able to commit to a long-term policy. Both assumptions are not very realistic.

${ }^{5}$ The water withdrawal tax for irrigation uses other than gravity irrigation is for example of 0.036 Euros per $\mathrm{m}^{3}$ (Conseil d'État 2010 [3], Sainteny 2012 [20]). The subsidies amounted to 60 Euros per ha in 2003 and 30 Euros per ha in 2006.
} 
Then, some restrictions on the parameters will be required to satisfy the above conditions:

$$
\begin{aligned}
\frac{\partial y_{i}}{\partial w_{i}} & =A f_{i}+B-M w_{i} \geq 0, \quad \frac{\partial^{2} y_{i}}{\partial w_{i}^{2}}=-M \leq 0, \\
\frac{\partial^{2} y_{i}}{\partial w_{i} \partial f_{i}} & =A \geq 0, \quad \frac{\partial y_{i}}{\partial f_{i}}=A w_{i}+E-K f_{i} \geq 0, \quad \frac{\partial^{2} y_{i}}{\partial f_{i}^{2}}=-K<0 .
\end{aligned}
$$

Using the second partial derivatives test, it is easy to verify that for the revenue function to be concave, the determinant of the Hessian matrix has to be positif, i.e. $p^{2} K M-p^{2} A^{2}>0$ which implies: ${ }^{6}$

$$
A^{2}-K M \leq 0
$$

The revenue of farmer $i$ at time $t$ is obtained by simply multiplying production by its price: $p y_{i}(t)$. The farmers are price- takers and the price $p_{i}$ of the agricultural product remains constant throughout the short planning horizon.

Concerning costs, irrigation $\operatorname{cost} c_{w}(\cdot)$ and costs of fertilizer application $c_{f}(\cdot)$ are considered. Irrigation $\operatorname{costs} c_{w}(\cdot)$ satisfy the following conditions:

$$
\frac{\partial c_{w}}{\partial w_{i}} \geq 0, \quad \frac{\partial^{2} c_{w}}{\partial w_{i}^{2}}=0, \quad \frac{\partial c_{w}}{\partial D} \geq 0, \quad \frac{\partial^{2} c_{w}}{\partial D^{2}}=0, \quad \frac{\partial^{2} c_{w}}{\partial w_{i} \partial D} \geq 0 .
$$

Based on Gisser and Sanchez [9] and its applications (see, e.g., Esteban and Albiac [8]), irrigation costs are specified as:

$$
c_{w}\left(w_{i}(t)\right)=(Z+C D(t)) w_{i}(t),
$$

where $Z$ and $C$ are positive parameters and $D(t)$ the distance between the soil surface and the water-table. The term $Z w_{i}$ represents the cost of distributing water, and $C D w_{i}$ is the waterpumping cost, which depends on the distance between the topsoil and the water-table and the pumped volume.

Following Roseta Palma (2003) [19], it is assumed that the cost of fertilizers can be satisfactorily approximated by the following linear relationship:

$$
c_{f}\left(f_{i}(t)\right)=L f_{i}(t),
$$

where $L$ is a positive parameter.

Concerning public policies, farmers pay a tax $\tau$ on the use of polluting fertilizer, and a $\operatorname{tax} \phi$ on individual water withdrawals. Consequently, the $i$ 's agent profit reads as follows:

$$
\Pi_{i}=\int_{0}^{T} \pi_{i}\left(w_{i}(t), f_{i}(t)\right) d t
$$

where

$$
\pi_{i}\left(w_{i}(t), f_{i}(t)\right)=p_{i} y_{i}\left(w_{i}(t), f_{i}(t)\right)-c_{w}\left(D(t), w_{i}(t)\right)-c_{f}\left(f_{i}(t)\right)-\tau f_{i}(t)-\phi w_{i}(t),
$$

and given the functional specifications:

$$
\pi_{i}\left(w_{i}, f_{i}\right)=p\left(A w_{i} f_{i}+B w_{i}+E f_{i}-\frac{1}{2} K f_{i}^{2}-\frac{1}{2} M w_{i}^{2}+G\right)-(Z+C D) w_{i}-L f_{i}-\tau f_{i}-\phi w_{i} .
$$

The following three remarks can be made:

\footnotetext{
${ }^{6}$ In some of the following examples, the simplifying assumption $A=0$ will be used. In that case, the determinant of the Hessian matrix is positif as by assumption

$$
-K M \leq 0
$$
}


1. There is no conceptual difficulty in extending the model to an oligopolistic setting where the farmers compete à la Cournot. It is also possible to consider a differentiated product (e.g., organic and regular), where the price does not only depend on the quantity of the product sold on the market, but also on the quality of irrigation water and the quantity of fertilizer used in farming. Obviously, the more sophisticated the model, the more complex the computation of the equilibrium policies.

2. Given the short-term planning horizon, farmer $i$ 's profit is not discounted over time. Including a discount factor does not pose any particular difficulty.

3. It is assumed that farmers do not take the dynamics of the water resource into account, except through the water pumping costs. It is possible to consider a case where farmers react to the evolution of the water-table, which could be observable, or the change in water quality, which could be measurable.

\subsection{The Dynamics}

The depth of the aquifer depends on withdrawals by farmers and on natural recharge. $r(t)$ denotes the mean recharge rate of the groundwater stock. Changes in $D$ are described by the differential equation

$$
\dot{D}(t)=g\left(\sum_{i} w_{i}(t), r(t)\right), \quad D(0)=D_{0} \quad \text { given, }
$$

where $D_{0}$ is a measurement of the initial water distance, with

$$
\frac{\partial g}{\partial w_{i}}>0, \quad \frac{\partial g}{\partial r}<0
$$

More precisely, the distance changes according to the linear differential equation:

$$
\dot{D}=\sum_{i} w_{i}-r, \quad D(0)=D_{0}
$$

that is the distance to the water table increases with the sum of individual withdrawals and decreases with the mean annual recharge rate.

The quality of the groundwater depends negatively on the quantity of fertilizer used by each farmer, and positively on the volume of the stock of water, i.e., the greater the stock of water, the higher the dilution (mitigation) capacity, and the better the quality. Further, it is assumed that the water agency can invest in an abatement program to improve the quality of water. Indeed, it is technically possible to influence quality by, for example, encouraging the use of nitrogen-fixing plants. Denote by $\sigma(t)$ the amount invested in abatement activity at time $t$. The change in the quality of the aquifer can then be written as

$$
\dot{Q}(t)=h\left(\sum_{i} f_{i}(t), \sigma(t), D(t)\right), \quad Q(0)=Q_{0} \quad \text { given, }
$$

where $Q_{0}$ is a measurement of the initial water quality, with

$$
\frac{\partial h}{\partial f_{i}}<0, \quad \frac{\partial h}{\partial \sigma}>0, \quad \frac{\partial h}{\partial D}<0 .
$$

With high fertilizer use, the quality degradation is high. Conversely, with high abatement activity, quality restoration is high. Likewise, when the distance to the water-table is long, and the water stock consequently low, degradation of water quality is high. When the distance to 
the water- table is short, and the stock of water consequently large, water quality degradation is low.

In the following, it is assumed that the water quality is satisfactorily approximated by the following differential equation:

$$
\dot{Q}=-\delta D \sum_{i} f_{i}(t)+\zeta \sigma(t), \quad Q(0)=Q_{0}
$$

where $\zeta$ and $\delta$ are positive scaling parameters. $\delta$ is a composite parameter taking into account the agricultural surface concerned with fertilizer applications, $S_{a}$, the dilution effect parameter, $\beta$, and the net natural decay rate, $\gamma$, measuring the percentage of nitrate eventually polluting the aquifer, and is given by: $\delta=\beta \gamma S_{a}$.

\subsection{The Water Agency}

Whereas it is easy to define an objective function for a farmer, defining one for the water agency is not that straightforward. Ideally, a welfare function should assess the value to society of any particular government policy. However, writing such a function is a highly complex problem from both a theoretical and a practical point of view. This paper adopts a pragmatic approach and assumes that the water agency uses its public policy to achieve (or approach as close as possible) pre-determined water quality and quantity levels over the planning horizon. More precisely, the water agency wishes to minimize the distance between the current and desired quality and quantity levels, that is,

$$
\min _{\tau, \phi, \sigma} \int_{0}^{T}\left(\alpha\left(Q(t)-Q_{b}\right)^{2}+(1-\alpha)\left(D(t)-D_{b}\right)^{2}\right) d t
$$

where $D_{b}$ the quantitative norm $Q_{b}$ the qualitative norm and $\alpha$ and $(1-\alpha)$ are positive weights that measure the importance of the quality and quantity goal, respectively. Typicall, norms may be thought as being set up in European Policies. Such an objective appears to be in line with the philosophy of public policy makers who would like to see a clear statement of what a government program aims to achieve.

To achieve the goals, the water agency can levy constant taxes (or give constant subsidies) on fertilizer and water use. Moreover, it can invest in a subsidy program for the use of nitrogen-fixing plants. The agency is indeed endowed with some financial resources at the initial instant of time, and is required to balance its books at the end of the planning horizon. The equilibrium-budget constraint at $T$ is:

$$
0=b_{0}+\int_{0}^{T}\left[\tau \sum_{i} f_{i}(t)+\phi \sum_{i} w_{i}(t)-g(\sigma(t))\right] d t,
$$

where $b_{0}$ is the available budget at time 0 , and $g(\sigma)$ is the cost of abatement activities. The above budget equation is an isoperimetric constraint that can be rewritten in the form of a state equation as follows:

$$
\dot{Y}(t)=\left[\tau \sum_{i} f_{i}(t)+\phi \sum_{i} w_{i}(t)-g(\sigma(t))\right] \quad \text { with } \quad Y(0)=b_{0} \quad \text { and } \quad Y(T)=0,
$$

where $Y(t)$ represents the funds available at time $t \in[0, T]$.

The following clarifications can be made:

1. The tax rates $\tau$ and $\phi$ do not vary with time and/or with the state of the system during the planning interval $[0, T]$. Such constant tax and subsidy policies were used by Krawczyk and Zaccour (1996) [13] in a dynamic game in which a local government aims to control pollution emissions by decentralized agents. 
2. No sign is imposed on the instruments $\tau$ and $\phi$. If optimization leads to negative values, then subsidies should be used rather than taxes.

3. In contrast to taxes, the investment in abatement activity can be a function of time or can be constant. In the section devoted to illustrations, the case where $\sigma$ is constant over time is analyzed.

4. Investment costs $g(\sigma)$ are assumed to be increasing and convex, with $g(0)=0$. In the section devoted to illustrations, the case of linear investments costs is analyzed, i.e. $g(\sigma)=s \sigma$, with $s$ being a positive parameter.

5. If the agency was allowed to have a surplus, then the budget constraint, equation (2.3) would become an inequality, i.e.,

$$
0 \leq b_{0}-\int_{0}^{T}\left(\tau \sum_{i} f_{i}(t)+\phi \sum_{i} w_{i}(t)-g(\sigma(t))\right) d t .
$$

To keep it simple, the case where the budget constraint is binding is analyzed.

6. For the sake of simplicity, the case where the water agency is contraint by a minimal profit for the farmers $\left(\Pi_{i}\left(\tau^{*}, \phi^{*}, \sigma^{*}\right) \geq \bar{\Pi}_{i}\right.$ with $\bar{\Pi}_{i}$ given $)$ is not explicitly considered. Farmers' profits in the examples are always positive however.

\section{Solutions}

In the previous section a finite-horizon differential game, with $N+1$ players ( $N$ farmers and a regulator) was defined (Dockner et al. 2000 [7]). The model involves three state variables: the quantity $D$ and quality $Q$ of water and the agency's budget, $Y$. In this section, the solutions to two scenarios are presented, namely the laisser-faire scenario and the regulation scenario.

\subsection{The Laisser-faire Scenario}

The case without regulation is given for $\phi=\tau=\sigma=0$. In this scenario the farmers maximize their profits individually without taking the dynamics into account, which amounts to optimizing at each instant of time

$$
\pi_{i}=p\left(A w_{i} f_{i}+B w_{i}+E f_{i}-\frac{1}{2} K f_{i}^{2}-\frac{1}{2} M w_{i}^{2}+G\right)-(Z+C D) w_{i}-L f_{i} .
$$

First-order optimality conditions are given by

$$
\begin{aligned}
& \frac{\partial \pi_{i}}{\partial w_{i}}=p\left(A f_{i}+B-M w_{i}\right)-(Z+C D)=0, \\
& \frac{\partial \pi_{i}}{\partial f_{i}}=p\left(A w_{i}+E-K f_{i}\right)-L f_{i}=0,
\end{aligned}
$$

which yields

$$
\begin{aligned}
\bar{w}_{i} & =\bar{w}=\frac{A(L-p E)+K(C D+Z-p B)}{p\left(A^{2}-K M\right)}, \\
\bar{f}_{i} & =\bar{f}=\frac{M(L-p E)+A(C D+Z-p B)}{p\left(A^{2}-K M\right)} .
\end{aligned}
$$

Consequently, the quantity and quality trajectories are given by

$$
D(t)=e^{-\rho t} D_{0}+\Theta^{\prime}\left(1-e^{-\rho t}\right),
$$




$$
Q(t)=Q_{0}-\int_{0}^{t}[\delta N f \tilde{f}(t) D(t)] d t
$$

where

$$
\rho=\frac{-N K C}{p\left(A^{2}-M K\right)}>0, \quad \text { and } \quad \Theta^{\prime}=-\frac{A(L-p E)+K(Z-p B)}{K C}-\frac{r}{\rho} .
$$

This benchmark solution allows to assess the impact of the regulation policy on physical (quantity and quality) and economic variables (farmers' profits).

\subsection{The Regulation Scenario}

Like in the benchmark scenario, the control variables of a farmer are water withdrawal $w_{i}$ and the quantity of fertilizer $f_{i}$. The water agency chooses the tax rates $\tau$ and $\phi$, which can assume any sign, and the investment in abatement activity $\sigma$, which is positive or zero. The game is played in a Stackelberg mode: the water agency plays the role of the leader and announces its strategy before the farmers make their decisions. Given the leader's announcement of the tax policy $(\tau, \phi, \sigma)$, the farmers play a Nash game and choose $w_{i}$ and $f_{i}$.

It is supposed that players employ open-loop strategies, that is, at the initial instant of time, they decide upon a strategy which depends only on time. This applies in particular to the leader, the followers playing a static game. It is well known that open-loop Stackelberg equilibria are in general time inconsistent. ${ }^{7}$ This means that given the opportunity to revise his strategy at an intermediate instant of time, the leader would like to choose another strategy than the one he selected at the initial instant of time. Therefore, an open-loop Stackelberg equilibrium only makes sense if the leader can credibly precommit to his strategy. In the present game it seems plausible to assume precommitment on the part of the water agency: in practice a tax scheme is announced from the outset and sometimes enforced by law.

\subsubsection{The Followers' Reaction Functions}

To solve for Stackelberg equilibrium, the reaction functions of the followers have to be determined first. Each farmer chooses the levels of inputs, $w_{i}(t)$ and $f_{i}(t)$, that maximize profits, given by equation (1). Water quality does not appear in the payoff function of a farmer, and hence it is irrelevant for this agent. Moreover, the budget constraint and the change in the water distance are supposed to be private information owned by the water agency, i.e., the farmers do not observe these state equations. Assuming an interior solution, the first-order equilibrium conditions are:

$$
\begin{aligned}
\frac{\partial \pi_{i}}{\partial w_{i}} & =p_{i} \frac{\partial y_{i}\left(w_{i}, f_{i}\right)}{\partial w_{i}}-\frac{\partial c_{w}\left(D, w_{i}\right)}{\partial w_{i}}-\phi=0, \\
\frac{\partial \pi_{i}}{\partial f_{i}} & =p_{i} \frac{\partial y_{i}\left(w_{i}, f_{i}\right)}{\partial f_{i}}-c_{f}^{\prime}\left(f_{i}\right)-\tau=0 .
\end{aligned}
$$

Equations (6)-(7) are the usual optimality conditions stating that, at the optimum, marginal revenues from production are equal to marginal costs. In equation (6), marginal revenues are due to the use of one additional unit of water. Marginal costs are given by marginal costs of pumping and distributing irrigation water and by the taxes paid per unit of water pumped. In equation (7), marginal revenues due to the use of one additional unit of fertilizer are equal to marginal costs of buying fertilizers and the tax paid per unit of fertilizer.

Given the specifications of the profit function in 2.1, farmer's reaction functions can be characterized in more detail, expressing his/her choice of input as a function of the tax and

\footnotetext{
${ }^{7}$ See, e.g., Martín-Herrán et al.(2005) [15] for examples where open-loop Stackelberg equilibria are time consistent.
} 
subsidy policy announced. The corresponding reaction functions depend on the distance to water, $D(t)$ and on both input taxes:

$$
\begin{gathered}
\tilde{w}_{i}(\tau, \phi, D)=\frac{A(L+\tau-p E)+K(C D+Z-p B+\phi)}{p\left(A^{2}-K M\right)}, \\
\tilde{f}_{i}(\tau, \phi, D)=\frac{M(L+\tau-p E)+A(C D+Z+\phi-p B)}{p\left(A^{2}-K M\right)} .
\end{gathered}
$$

Recalling that $p\left(A^{2}-K M\right)<0$, and that abatement activities and water quality are not part of the farmers' payoffs, the analysis of the above reaction functions allow for the following comments:

1. The farmers decrease both their water and fertilizer use when the distance to the watertable increases:

$$
\frac{\partial \tilde{w}_{i}}{\partial D}=\frac{K C}{p\left(A^{2}-K M\right)}<0, \quad \frac{\partial \tilde{f}_{i}}{\partial D}=\frac{A D}{p\left(A^{2}-K M\right)}<0 .
$$

So although the farmers are myopic in the sense that they do not account for the dynamics in their optimization program, their decisions still depend on $D$ because the distance to the water- table affects their profits. The quality of the groundwater does not appear in their profit function and therefore does not affect their choice of input levels.

2. The reaction functions are symmetric, that is $f_{i}=f$ and $w_{i}=w$. This a by-product of the fact that parameters are the same for all the farmers.

\subsubsection{The Leader's Problem}

The leader solves a non- standard optimal- control problem because the water agency is assumed to set constant taxes throughout the planning horizon. He maximizes equation (4) constraint by the dynamics (2), (3) and (5). Omitting from now on the time argument when no ambiguity can arise and accounting for the farmers' reactions functions, the dynamics become

$$
\begin{aligned}
\dot{Y} & =\tau N \tilde{f}(\tau, \phi, D)+\phi N \tilde{w}(\tau, \phi, D)-g(\sigma), \quad Y(0)=b_{0}, \quad Y(T)=0, \\
\dot{D} & =N \tilde{w}(\tau, \phi, D)-r, \quad D(0)=D_{0}, \\
\dot{Q} & =-\delta D N \tilde{f}(\tau, \phi, D)+\zeta \sigma \quad Q(0)=Q_{0} \quad \text { given. }
\end{aligned}
$$

The leader's Hamiltonian reads as follows:

$$
\begin{gathered}
\left.H_{L}\left(D, \mu^{D}, Q, \mu^{Q}, Y, \mu^{Y}, \tau, \phi, \sigma\right)\right)=\alpha\left(Q-Q_{b}\right)^{2}+(1-\alpha)\left(D-D_{b}\right)^{2} \\
\mu^{D}(N \tilde{w}(\tau, \phi, D)-r)+\mu^{Q}(-\delta D N \tilde{f}(\tau, \phi, D)+\zeta \sigma) \\
+\mu^{Y}(\tau N \tilde{f}(\tau, \phi, D)+\phi N \tilde{w}(\tau, \phi, D)-g(\sigma))
\end{gathered}
$$

where the $\mu^{D}, \mu^{Q}$ and $\mu^{Y}$ are adjoint variables appended to the state variables $D, Q$ and $Y$. Substituting for $\tilde{w}(\tau, \phi, D)$ and $\tilde{f}(\tau, \phi, D)$, this gives:

$$
\begin{gathered}
\left.H_{L}\left(D, \mu^{D}, Q, \mu^{Q}, Y, \mu^{Y}(t), \tau, \phi, \sigma\right)\right)= \\
\alpha\left(Q-Q_{b}\right)^{2}+(1-\alpha)\left(D-D_{b}\right)^{2}-r \mu^{D}+\zeta \sigma \mu^{Q}-\mu^{Y} g(\sigma) \\
+\left(\mu^{D}+\phi \mu^{Y}\right) N \frac{A(L+\tau-p E)+K(C D+Z-p B+\phi)}{p\left(A^{2}-K M\right)} \\
+\left(-\delta D \mu^{Q}+\tau \mu^{Y}\right) N \frac{M(L+\tau-p E)+A(C D+Z+\phi-p B)}{p\left(A^{2}-K M\right)} .
\end{gathered}
$$


Assuming an interior solution, the first-order optimality conditions include the three state equations in (8)-(10) and the following equations:

$$
\begin{aligned}
& \dot{\mu}^{D}=-\frac{\partial H_{L}}{\partial D} \\
& =-2(1-\alpha)\left(D-D_{b}\right)-\left[\left(\mu^{D}+\phi \mu^{Y}\right) K+\left(-\delta D \mu^{Q}+\tau \mu^{Y}\right) A\right] \frac{N C}{p\left(A^{2}-K M\right)}+ \\
& \delta \mu^{Q} N \frac{M(L+\tau-p E)+A(C D+Z+\phi-p B)}{p\left(A^{2}-K M\right)}, \quad \mu^{D}(T)=0, \\
& \dot{\mu}^{Q}=-\frac{\partial H_{L}}{\partial Q}=-2 \alpha\left(Q-Q_{b}\right), \quad \mu^{Q}(T)=0, \\
& \dot{\mu}^{Y}=-\frac{\partial H_{L}}{\partial Y}=0 \\
& \int_{0}^{T} \frac{\partial H_{L}}{\partial \tau} d t=0 \Leftrightarrow \int_{0}^{T}\left[\left(\mu^{D}+\phi \mu^{Y}\right) A+\left(-\delta D \mu^{Q}+\tau \mu^{Y}\right) M\right] d t=0, \\
& \int_{0}^{T} \frac{\partial H_{L}}{\partial \phi} d t=0 \Leftrightarrow \\
& \int_{0}^{T}\left(\left(\mu^{D}+2 \phi \mu^{Y}\right) K+\mu^{Y}[A(L+\tau-p E)+K(C D+Z-p B)]+\left(-\delta D \mu^{Q}+\tau \mu^{Y}\right) A\right) d t=0, \\
& \frac{\partial H_{L}}{\partial \sigma}=0 \Leftrightarrow \zeta \mu^{Q}-\mu^{Y} g^{\prime}(\sigma)=0 \quad \text { if } \quad \sigma=\sigma(t), \\
& \int_{0}^{T} \frac{\partial H_{L}}{\partial \sigma} d t=0 \Leftrightarrow \int_{0}^{T} \zeta \mu^{Q}-\mu^{Y} g^{\prime}(\sigma) d t=0 \quad \text { if } \quad \sigma=c t e .
\end{aligned}
$$

In sum, the leader's optimality conditions include 9 equations and same number of unknowns. Clearly, it is not possible to solve this system analytically and it is therefore necessary to resort to numerical simulations. However, before moving forward, the following comments can be made:

1. The optimality conditions in (14)-(17) take the form of an integral because of the assumption that the water agency restricts its choice of taxes or abatement to constant ones.

2. As the values of the state variable $Y(t)$ are given at 0 and $T$, the adjoint variable $\mu^{Y}$ is free.

3. When considering the abatement as a function of $t$, the optimality condition in (16) states that the optimal level of abatement activities is determined following the rule of marginal cost (given by $\mu^{Y} g^{\prime}(\sigma)$ ) equals the marginal gain from quality improvement, i.e., $\zeta \mu^{Q}$ ).

4. The variation over time in the shadowprice of quality corresponds to the weighted difference between the observed quality and its target value at time $t$ (see (12)). 


\subsubsection{Optimal tax policies and quantity-quality trajectories}

The problem can be solved explicitly for the quantity and quality state variables, which gives:

$$
\begin{aligned}
& D(t, \phi, \tau)=e^{-\rho t} D_{0}+\Theta(\tau, \phi)\left(1-e^{-\rho t}\right), \\
& Q(t, \phi, \tau)=Q_{0}-\int_{0}^{t}[\delta N \tilde{f(t) D(t)-\zeta \sigma(t)] d t .}
\end{aligned}
$$

where

$$
\rho=\frac{-N K C}{p\left(A^{2}-M K\right)}>0, \quad \text { and } \quad \Theta(\tau, \phi)=-\frac{A(L+\tau-p E)+K(Z-p B+\phi)}{K C}-\frac{r}{\rho} .
$$

Further, without completely solving the first- order conditions, the following results can be stated, showing that the leader's tax policies have the desired impact on quantity and quality.

Proposition 1 The farmers use less water (fertilizer) inputs than in the laisser-faire case when either the water or the fertilizer inputs are taxed.

Proof. See Appendix(A.1).

Proposition 2 The use of optimal input taxes leads to both better water quality and a shorter distance to the water- table, compared to the laisser-faire case, whatever the type of input taxes used, a water tax or a fertilizer tax.

Proof. See Appendix(A.2).

Propositions 1 and 2 ensure that the tax policies play as intended. However, they do not indicate how the optimal policy-mix should be designed, i.e. what the amount of each tax and subsidy is. It is possible to determine numerically the set of constant policies which allows the water agency to minimize the (quadratic) distance from the desired quantity and quality goal and to respect the budget constraint. In the following section, some examples of different sets of such policies are presented.

\section{Illustrations}

In this section, a few illustrative examples underline the difficulties of setting multi-objectif tax policies. As it is not possible to solve the leader's optimality conditions analytically, numerical simulations are used. Some of the examples are extreme but provide insight into the equilibrium behavior of the agency and of the farmers. The model has 21 parameters, namely,

$$
\begin{aligned}
\text { Production function parameters and price } & : A, B, E, K, M, G, p, \\
\text { Water pumping cost } & : Z, C, \\
\text { Fertilizer cost } & : L, \\
\text { Parameters in state equations } & : D_{0}, Q_{0}, Y_{0}, \delta, \zeta, r, s, \\
\text { Target values and weight } & : D_{b}, Q_{b}, \alpha, \\
\text { Other parameters } & : T, N .
\end{aligned}
$$

The illustration is based on several realistic production and cost functions, taken from the literature. The values for the production function are taken from Larson et al. 1996 [14] as listed in Table 1 and illustrated in Figure $1 .^{8}$

\footnotetext{
${ }^{8}$ Quadratic terms are multiplied by 2 because of the terms: $\frac{1}{2} K f^{2}-\frac{1}{2} M w^{2}$.
} 
Table 1: Production function parameter values

\begin{tabular}{l|r} 
Parameter & value \\
\hline $\mathrm{A}$ & 0.000002 \\
$\mathrm{~B}$ & 0.00151 \\
$\mathrm{E}$ & 0.000535 \\
$\mathrm{G}$ & 2.52 \\
$\mathrm{~K}$ & 0.00001076 \\
$\mathrm{M}$ & 0.00000177
\end{tabular}

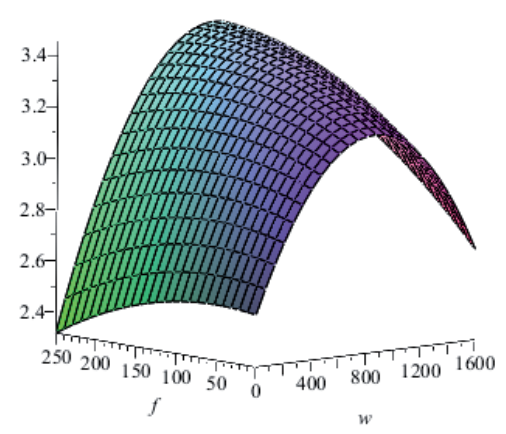

Figure 1: Production function

Water input is measured in $\mathrm{mm} / \mathrm{ha}$, fertilizer in $\mathrm{kg} / \mathrm{ha}$. Input costs and the data concerning the groundwater resource ${ }^{9}$ are taken from Roseta Palma (2003) [19]. As indicated in Table 2, the abatement cost parameter, $s$, is set to 0.05 , the abatement efficiency $\zeta$ is equal to 0.1 and the composite parameter, $\delta$, is equal to 0.5 . Next, a short time horizon of one year is considered and it is assumed that 10 farmers have access to the aquifer. Note that without using-up the aquifer the quantity of available water is $550 \mathrm{~mm}-\mathrm{ha}$.

As shown in Table 3, in the first example the agency has no initial financial endowment, i.e. $b_{0}=0$. Also, at the beginning, the aquifer is completely replenished, i.e. $D(0)=0$ and the quality parameter is zero, i.e. $Q(0)=0$. The quantity goal is set to $D_{b}=400$, the quality goal to $Q_{b}=-5000 .{ }^{10}$ These goals are exogenously given and do not represent optimal values to be achieved. It can hence be optimal for the water agency to only approach these norms. Finally, it is assumed that the water agency attaches the same importance to quantity and quality management, $\alpha=0.5$. This first set of parameter values is referred to as the baseline case.

\footnotetext{
${ }^{9}$ The recharge rate of $\mathrm{r}=5.5$ million $\mathrm{m}^{3}$ in Roseta Palma corresponds to a recharge in terms of distance to the water- table of $r /(S A)=2.75 \mathrm{~m}$

${ }^{10}$ Note that a quality goal of $-5000 \mathrm{~kg}$ corresponds to a total load of fertilizer of less than $1 \mathrm{mg} / \mathrm{l}$ in the annual recharge of 5,5 million $\mathrm{m}^{3}$. In the following, less stringent values are considered. Typically, $-250000 \mathrm{~kg}$ correspond to a total annual load of fertilizer in the recharge of $45 \mathrm{mg} / \mathrm{l}$.
} 
Table 2: Parameter values 1

\begin{tabular}{l|c|c|r} 
Name & parameter & unit & value \\
\hline Price & $\mathrm{p}$ & $€ / \mathrm{kg}$ & 0.5 \\
Irrigation costs & $\mathrm{Z}$ & $€ / \mathrm{mm}-\mathrm{ha}$ & 0.23 \\
Pumping costs & $\mathrm{C}$ & mm-ha per $\mathrm{m}$ & 0.003 \\
Fertilizer costs & $\mathrm{L}$ & $€ / \mathrm{kg}$ & 0.4 \\
\hline Recharge rate & $\mathrm{r}$ & $\mathrm{mm} / \mathrm{year}$ & 2750 \\
Aquifer surface & $\mathrm{S}$ & $\mathrm{ha}$ & 2000 \\
Storativity coefficient & $\mathrm{A}$ & & 0.1 \\
Agricultural surface & $\mathrm{S}$ & $\mathrm{ha}$ & 1000 \\
\hline Abatement costs & $\mathrm{S}$ & & 0.05 \\
Abatement efficiency & $\mathrm{S}$ & & 0.1 \\
Dilution and pollution parameter & $\delta$ & & 0.5 \\
\hline Time horizon & $\mathrm{T}$ & year & 1 \\
Number of players & $\mathrm{N}$ & & 10
\end{tabular}

Table 3: Parameter values 2: baseline case

\begin{tabular}{l|c|c|r} 
Name & parameter & unit & value \\
\hline Initial budget & $\mathrm{Y}(0)=\mathrm{b}_{0}$ & $€$ & 0 \\
Initial distance to water table & $\mathrm{D}(0)$ & $\mathrm{mm}$ & 0 \\
Initial quality measure & $\mathrm{Q}(0)$ & $\mathrm{kg}$ & 0 \\
\hline Quantity target & $\mathrm{D}_{b}$ & $\mathrm{~mm}$ & 400 \\
Quality target & $\mathrm{Q}_{b}$ & $\mathrm{~kg}$ & -5000 \\
Target weight & $\alpha$ & & 0.5
\end{tabular}

\subsection{Results of the baseline case}

In the baseline case, the optimal policy-mix is given by:

$$
\phi=3.01, \quad \tau=4.87, \quad \sigma=217502, \quad \text { with } \quad \mu^{Y}=79.04 .
$$

The optimal policy consists in taxing water and fertilizer inputs at 3.01 Euros per mm-ha and 4.87 Euros per $\mathrm{kg}$ throughout the year. In addition, it is best to invest in green manure, namely 21752 Euros per farmer and per year.

Table 4 lists some characteristic values for the optimal solution and for the laisser-faire scenario. In the laisser-faire scenario, farmers lower the water table (i.e. increase the distance to the water table) and reduce water quality considerably below the desired goals. Farmers use $466 \mathrm{~mm}$-ha of groundwater over the year in the laisser-faire scenario, as opposed to the optimal policy of $337 \mathrm{~mm}$-ha. Likewise, they use $129 \mathrm{~kg} / \mathrm{ha}$ of fertilizer, as opposed to the optimal policy of $14 \mathrm{~kg} / \mathrm{ha}$. Hence, farmers use too much inputs with respect to the desired outcome. Not surprisingly, farmers' gains under the laisser-faire scenario are higher (13 563 Euros per ha) than with the regulation scenario, where they only earn 13077 Euros per ha. This means that the water agency finances his/her policy by reducing farmers revenues. Finally note that it is optimal to tax fertilizer inputs more than water inputs. This is due to the very stringent quality goal in this example.

The evolution of the state and decision variables is illustrated in Figures 2, 3 and 4 . The desired distance to the water- table and the desired water quality level are represented by the 
Author-produced version of the article published in Environmental Science \& Policy, 2014, N44, p. 201-214. The original publication is available at http://www.sciencedirect.com/science/article/pii/S1462901114001580 Doi: 10.1016/j.envsci.2014.08.002

Table 4: Results baseline case

\begin{tabular}{l|l|r|r} 
Variable & unit & With policy & Laisser-faire \\
\hline$D(T)$ & $\mathrm{mm}$ & 624 & 1914 \\
$Q(T)$ & $\mathrm{kg}$ & -3181 & -867930 \\
$\int_{0}^{T} w_{i}$ & $\mathrm{~mm} / \mathrm{ha}$ & 337 & 466 \\
$\int_{0}^{T} f_{i}$ & $\mathrm{~kg} / \mathrm{ha}$ & 14 & 129 \\
$\int_{0}^{T} \pi_{i}$ & $€ / \mathrm{ha}$ & 13077 & 13563 \\
\hline
\end{tabular}

dotted lines. The laissez-faire case is represented by the dashed (black) lines. Paths including the optimal policy are represented by solid (red) lines. 
Author-produced version of the article published in Environmental Science \& Policy, 2014, N 44 , p. 201-214. The original publication is available at http://www.sciencedirect.com/science/article/pii/S1462901114001580 Doi: 10.1016/j.envsci.2014.08.002
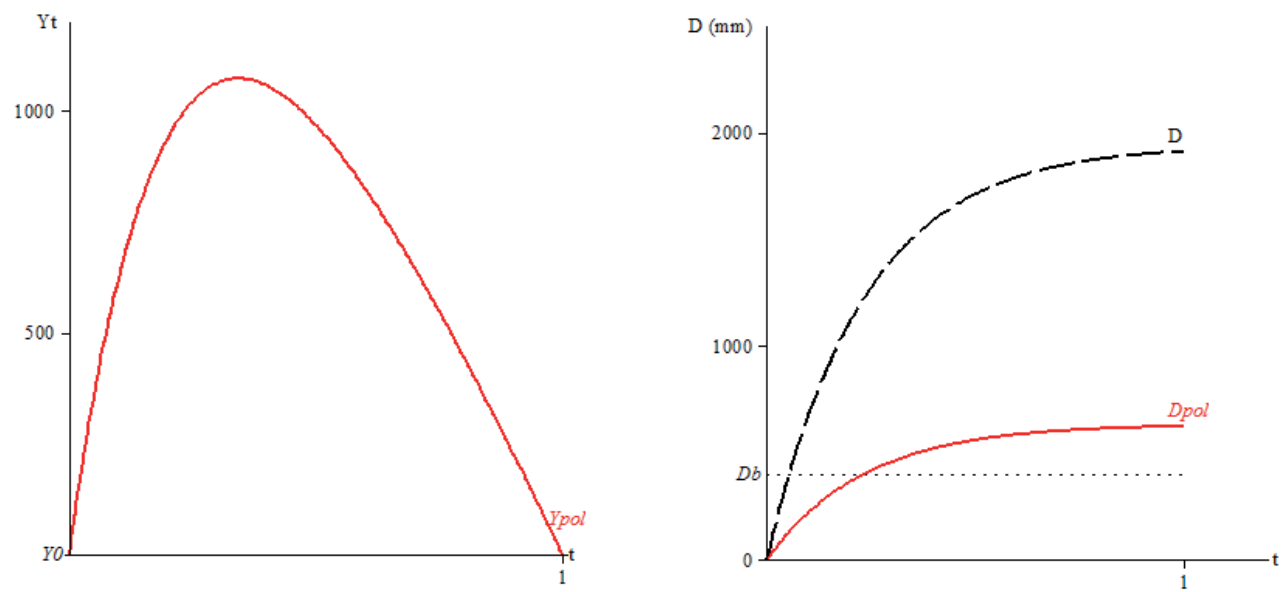

Figure 2: Budget (left) and distance to the water table (right) in the baseline case
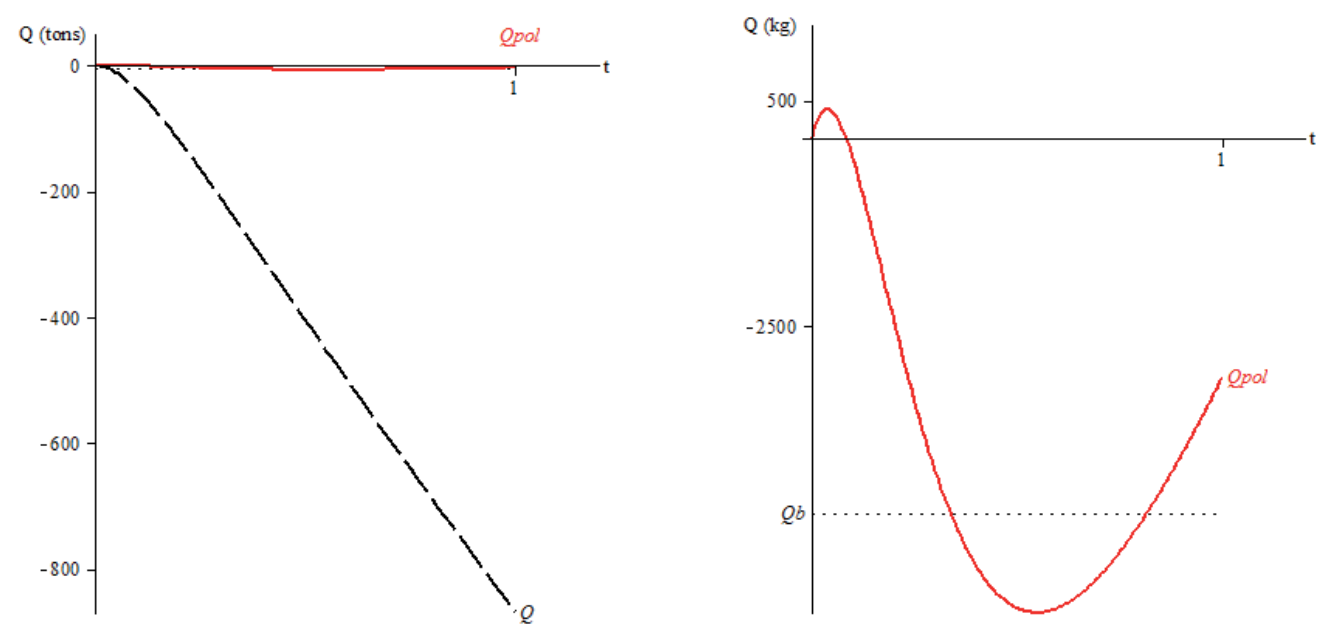

Figure 3: Quality (left) with zoom on optimal policy (right) in the baseline case
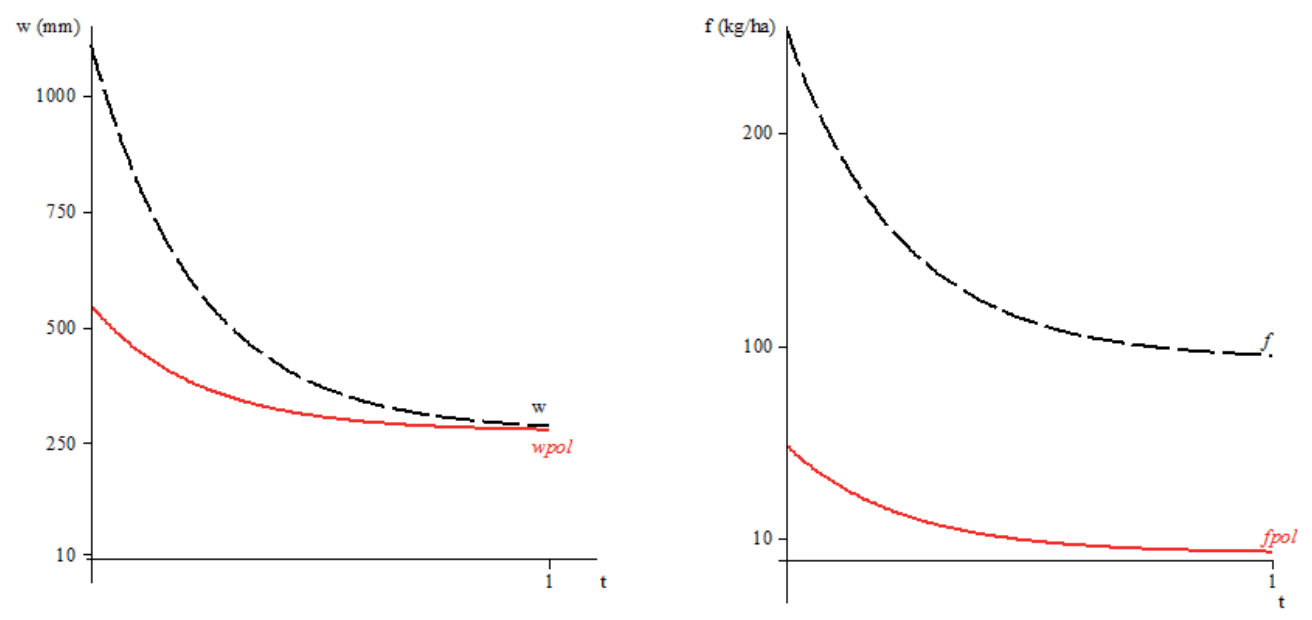

Figure 4: Use of inputs: water (left), fertilizer (right) in the baseline case 


\subsection{Case with changes in the initial budget}

Clearly, the optimal equilibrium solution depends on the budget constraint. In the baseline case, the initial endowment was set to be zero. Alternatively, it can be assumed the water agency has an initial endowment, which is the case in most European countries. Consider the cases where $b_{0}=50000, b_{0}=100000$ and $b_{0}=500000$. The optimal solutions are indicated in Table 5 .

Table 5: Results when $b_{0}$ changes

\begin{tabular}{l|l|r|r|r|r} 
Variable & unit & $b_{0}=0^{*}$ & $b_{0}=50000$ & $b_{0}=100000$ & $b_{0}=500000$ \\
\hline$D(T)$ & $\mathrm{mm}$ & 624 & 1038 & 1327 & 2690 \\
$Q(T)$ & $\mathrm{kg}$ & -3181 & -1126 & 929 & 17362 \\
$\int_{0}^{T} w_{i}$ & $\mathrm{~mm} / \mathrm{ha}$ & 337 & 379 & 408 & 544 \\
$\int_{0}^{T} f_{i}$ & $\mathrm{~kg} / \mathrm{ha}$ & 14 & 36 & 50 & 109 \\
$\int_{0}^{T} \pi_{i}$ & $€ / \mathrm{ha}$ & 13077 & 13178 & 13274 & 13941 \\
\hline$\phi$ & $€ / \mathrm{mm}$ & 3.01 & 1.90 & 1.10 & -2.71 \\
$\tau$ & $€ / \mathrm{kg}$ & 4.87 & 4.12 & 3.68 & 1.84 \\
$\sigma$ & $€ /$ year & 217502 & 1173645 & 2126272 & 9745901 \\
\hline
\end{tabular}

* Baseline case. Values rounded.

Having access to an initial endowment, the water agency would set lower taxes and invest more in green manure. The water quality is generally improved although water and fertilizer use may increase in comparison with the baseline case. This is due to the possibility of efficient investment in green manure. ${ }^{11}$ As water input use increases, the distance to the water table increases. Hence, increasing the budget leads to better quality performance but worse quantity performance.

For example the optimal policy for $b_{0}=100000$ can be depicted in more detail in Table 6 and in Figures 5, 6 and 7. As before, the black dashed lines represent the laisser-faire case and the red solid lines the optimal policy. Note that the laisser-faire scenario is the same as in the baseline case.

Table 6: Results when $b_{0}=100000$

\begin{tabular}{l|l|r|r} 
Variable & unit & With policy & Laisser-faire \\
\hline$D(T)$ & $\mathrm{mm}$ & 1327 & 1914 \\
$Q(T)$ & $\mathrm{kg}$ & 929 & -867910 \\
$\int_{0}^{T} w_{i}$ & $\mathrm{~mm} / \mathrm{ha}$ & 408 & 466 \\
$\int_{0}^{T} f_{i}$ & $\mathrm{~kg} / \mathrm{ha}$ & 50 & 129 \\
$\int_{0}^{T} \pi_{i}$ & $€ / \mathrm{ha}$ & 13274 & 13563 \\
\multicolumn{2}{l}{ Values rounded. }
\end{tabular}

Comparing the right-hand side of Figures 2 and 5 it is clear that the optimal distance to the water table increases with an increase in the intial budget. Comparing Figures 3 and 6, it can be seen that overall quality is higher with a higher initial budget. Finally, comparing Figures 4 and 7 , it is obvious that water and fertilizer use have increased in the second example, especially in the early periods of the year.

\footnotetext{
${ }^{11}$ When the initial budget is extremely high (e.g. 500000 Euros which corresponds to 50000 Euros per farmer), it is even optimal to subsidize water use.
} 

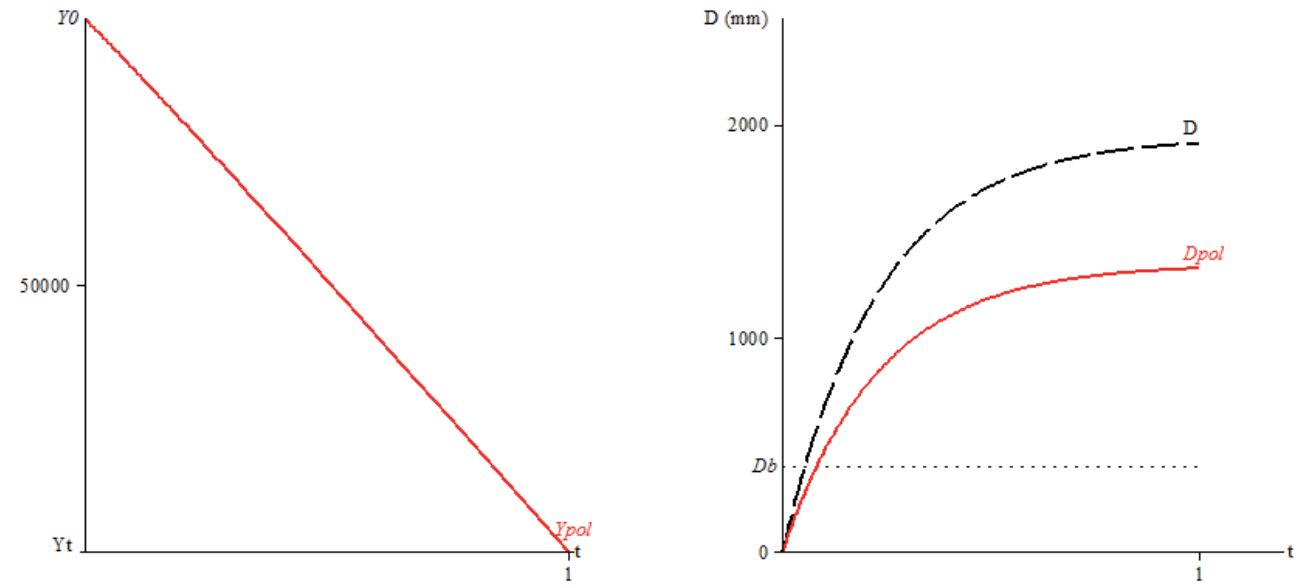

Figure 5: Budget (left) and distance to water table (right) with initial budget of 100000 Euros
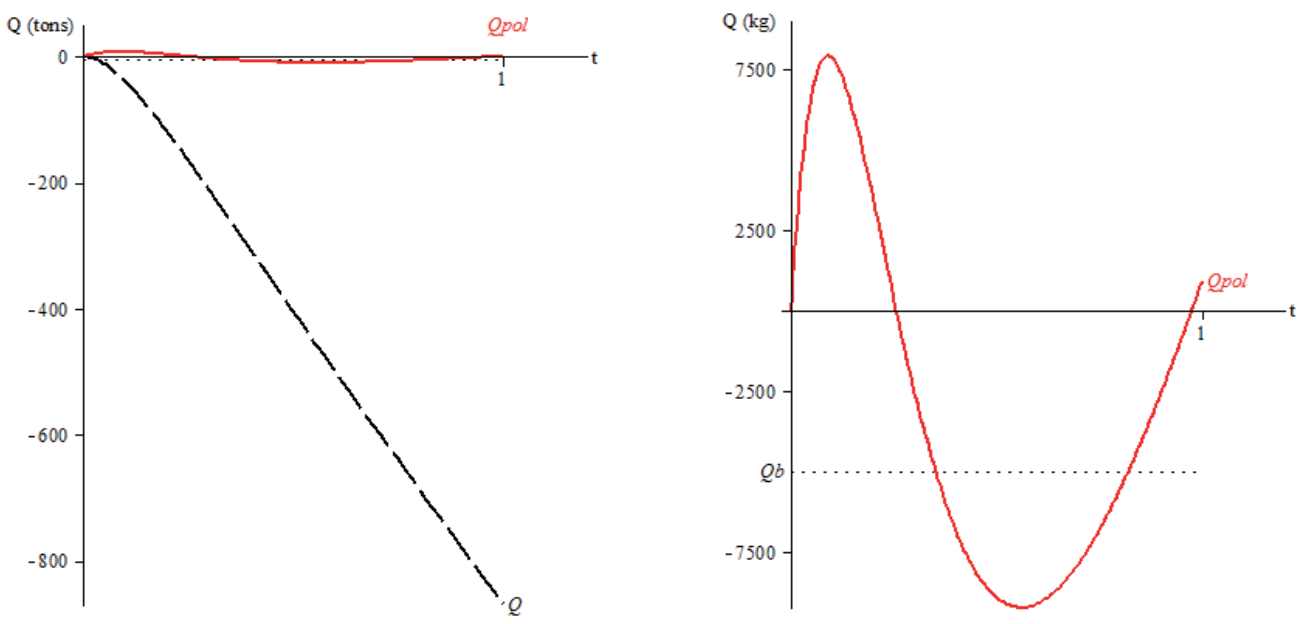

Figure 6: Quality (left) with zoom on optimal policy (right) with initial budget of 100000 Euros
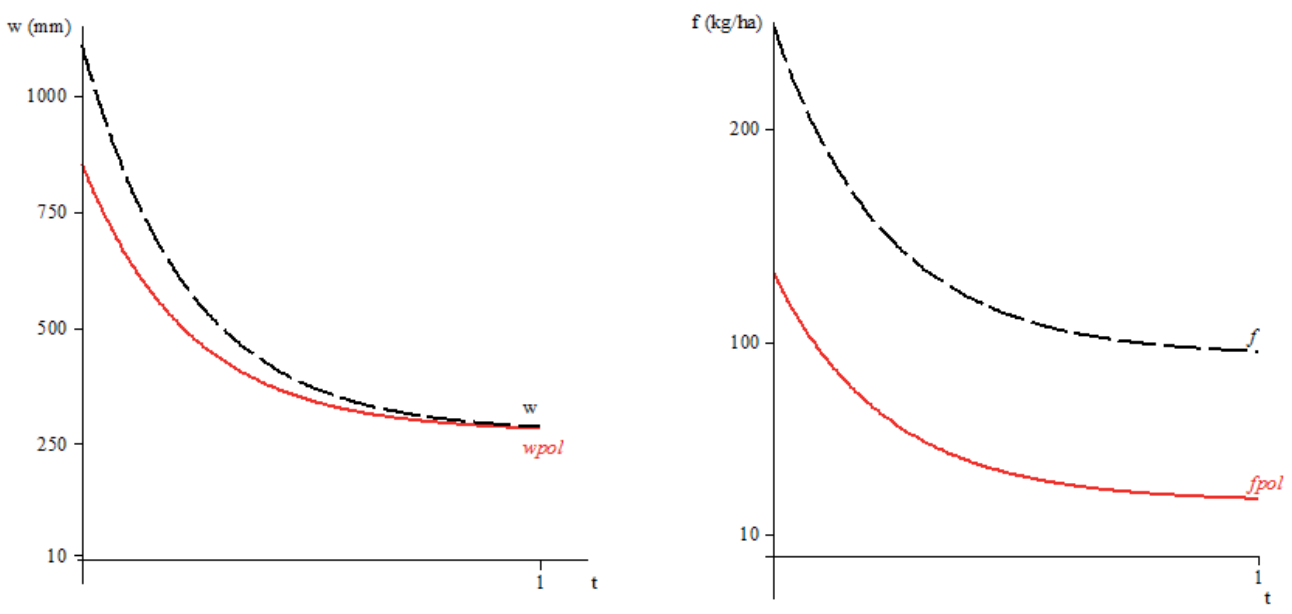

Figure 7: Input use: water (left), fertilizer (right) with initial budget of 100000 Euros 


\subsection{Case with changes in the quality goal}

For the baseline case, a strict quality norm was considered. In the following, cases with a less stringent quality goal are taken into account, i.e. $Q_{b}=-50000, Q_{b}=-100000$ and $Q_{b}=-250000$. These values correspond to an equivalent of $9 \mathrm{mg} / \mathrm{l}$ of recharge in the first case, $18 \mathrm{mg} / \mathrm{l}$ in the second, and $45 \mathrm{mg} / \mathrm{l}$ in the third case. Optimal solutions are given in Table 7 .

Table 7: Results of models with different quality norms

\begin{tabular}{l|l|r|r|r|r} 
Variable & unit & $Q_{b}=-5000^{*}$ & $Q_{b}=-50000$ & $Q_{b}=-100000$ & $Q_{b}=-250000$ \\
\hline$D(T)$ & $\mathrm{mm}$ & 624 & 219 & 301 & 472 \\
$Q(T)$ & $\mathrm{kg}$ & -3181 & -80416 & -157625 & -389109 \\
$\int_{0}^{T} w_{i}$ & $\mathrm{~mm} / \mathrm{ha}$ & 337 & 297 & 305 & 322 \\
$\int_{0}^{T} f_{i}$ & $\mathrm{~kg} / \mathrm{ha}$ & 14 & 128 & 157 & 219 \\
$\int_{0}^{T} \pi_{i}$ & $€ / \mathrm{ha}$ & 13077 & 13054 & 13197 & 13650 \\
\hline$\phi$ & $€ / \mathrm{mm}$ & 3.01 & 5.46 & 5.48 & 5.55 \\
$\tau$ & $€ / \mathrm{kg}$ & 4.87 & -1.66 & -3.10 & -6.26 \\
$\sigma$ & $€ /$ year & 217501 & 281750 & 237422 & 83616 \\
\hline
\end{tabular}

* Baseline case. Values rounded.

With a less stringent quality norm, it becomes optimal to subsidize fertilizer use, which will increase with respect to the baseline case. The quality obtained is less than previously but this is intended, as the quality norm has changed. To compensate for increased fertlizer use, investments in green manure increase but water use is also more heavily taxed and consequently decreases. Hence the quality obtained is less important but the quantity obtained is better than in the previous example.

It is interesting to compare the laisser-faire and the optimal solution of the particular case where $Q_{b}=-100000$. As shown in Table 8, optimal fertilizer use now increases to $157 \mathrm{~kg}$ per ha which even exceeds the laisser-faire case. On the other hand, overall water use decreased to $305 \mathrm{~mm}$ per ha, still below the laisser-faire level. The optimal evolution of the state and decision variables is shown in figures 8,9 and 10 .

Table 8: Results with quality norm $Q_{b}=-100000$

\begin{tabular}{l|l|r|r} 
Variable & unit & $Q_{b}=-100000$ & Laisser-faire \\
\hline$D(T)$ & $\mathrm{mm}$ & 301 & 1914 \\
$Q(T)$ & $\mathrm{kg}$ & -157625 & -867910 \\
$\int_{0}^{T} w_{i}$ & $\mathrm{~mm} / \mathrm{ha}$ & 305 & 466 \\
$\int_{0}^{T} f_{i}$ & $\mathrm{~kg} / \mathrm{ha}$ & 157 & 129 \\
$\int_{0}^{T} \pi_{i}$ & $€ / \mathrm{ha}$ & 13197 & 13563 \\
\hline
\end{tabular}

Values rounded.

Comparing the right-hand-side of Figures 2 and 8, it is clear that the optimal distance to the water- table decreases when the quality norm is less stringent. The quality goal can more easily be reached (see Figure 9) which helps to achieve the quantity goal. Comparing figures 4 and 10 shows that water use decreases in the early periods of the year. Moreover, fertilizer use increases not only in the early periods of the year but also during the later periods of the year, when it even exceeds the laisser-faire level. 
Author-produced version of the article published in Environmental Science \& Policy, 2014, N 44 , p. 201-214. The original publication is available at http://www.sciencedirect.com/science/article/pii/S1462901114001580 Doi: 10.1016/j.envsci.2014.08.002
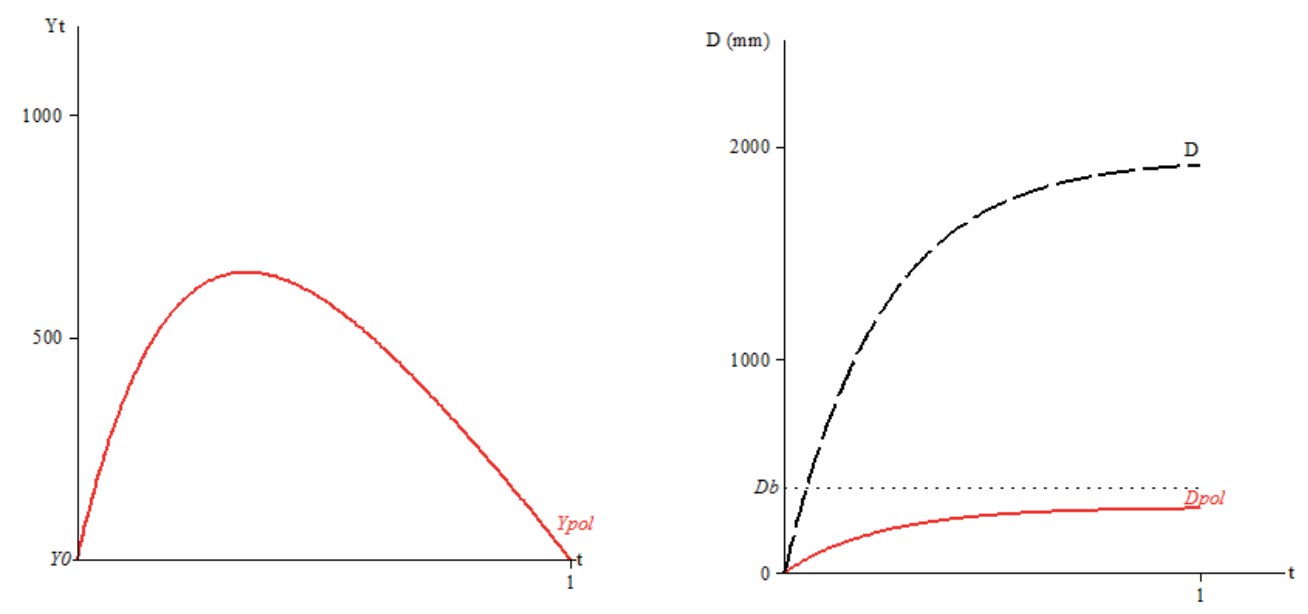

Figure 8: Budget (left) and distance to the water table (right) with quality norm $Q_{b}=-100000$
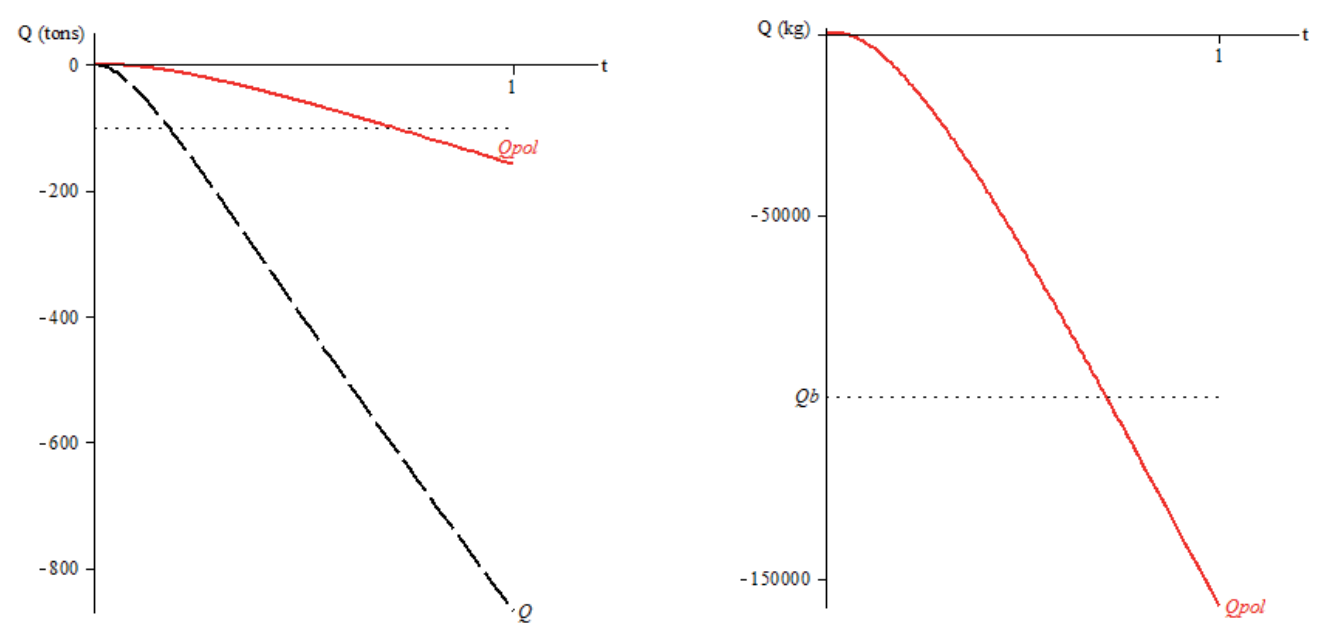

Figure 9: Quality (left) with zoom on optimal policy (right) with quality norm $Q_{b}=-100000$
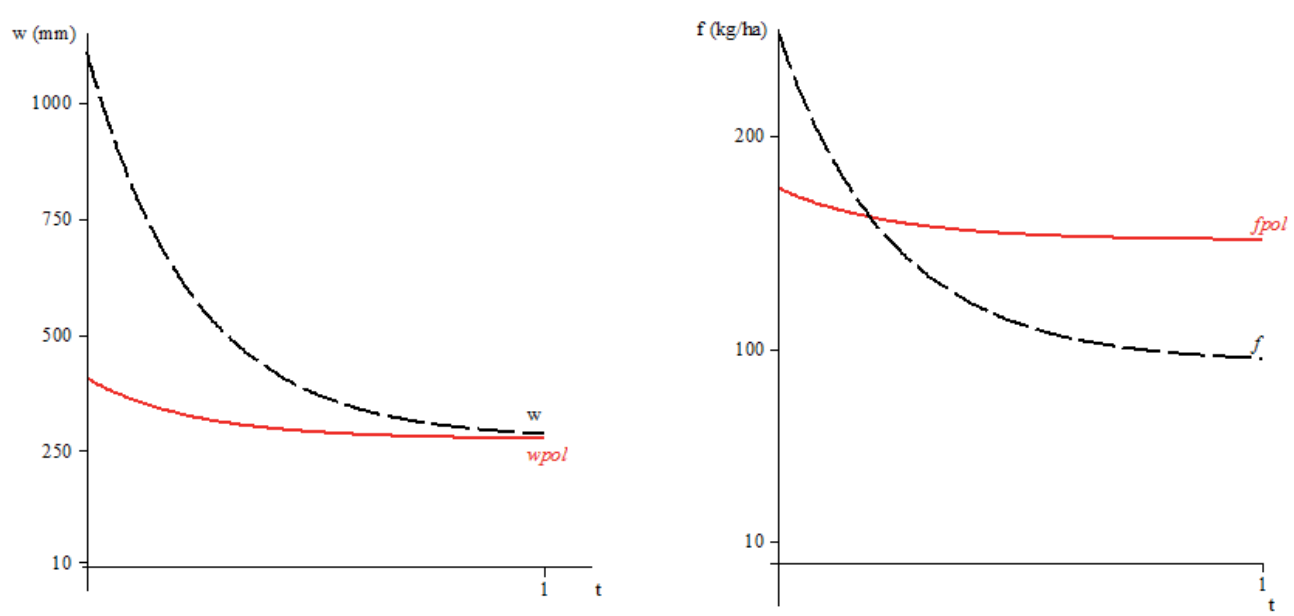

Figure 10: Input use: water (left), fertilizer (right) with quality norm $Q_{b}=-100000$ 


\subsection{Concluding Remarks on the Illustration}

First note that a higher budget leads to higher investment in green manure but also allows a greater fertilizer use. The quality goal is improved, although fertilizer use has increased, because the green manure investment is efficient. However, greater fertlizer use leads to a concomittant increase in water inputs and consequently, the quantity goal is less well respected.

On the other hand, a less stringent quality norm leads to subsidies on fertilizer inputs which are financed by taxes on water use. Fertilizer use increases but water use decreases and consequently, the quantity goal is more easily reached, because the quality goal is less strict.

In some examples, optimal quantity or quality trajectories "overshoot" the desired policy goal. This is due to two facts: first, the nature of the optimization problem, which contains multiple constraints, makes it impossible to reach all the "desired" situations at the same time. Second, the objective of minimizing the quadratic distance to the desired goals allows itself for some overshooting. This can be justified if exogenous norms do not indicate exact values but represent a desirable range to be reached over one year. The main conclusion from the above examples is that it is not trivial to set second best policies in an optimal manner. The model can help to set optimal amounts of investment and input taxes, as shown above.

\section{Concluding Remarks}

A model of groundwater management was set up in which a group of farmers overexploit the water stock and causes excessive pollution, by using too much irrigation water and fertilizer. Considering the fact that a dynamic taxation policy is not easy to implement for a water agency, but that commitment to a constant policy over one fiscal year was not a major problem for the agency, the analysis searches a set of constant policies that allows the regulator to bring the water resource close to the desired quantity and quality goals. To identify the optimal policy-mix, a Stackelberg game was constructed. Analytical results show that, in addition to the usual first order conditions, some special conditions are needed to account for the fact that in practice, the water agency can only impose constant policies. Analytical results also show how the farmers' choice of inputs and the water agency's optimal policy choice depend on the other parameters of the model. Model simulations show that the optimal policy-mix is non-trivial, depending on the context in which the water agency takes its decisions, namely whether quantity and quality goals are far from the current state and whether the budget constraint is strong or not.

The analysis can be extended in different directions. First, it would be interesting to compare the constant policies derived here with time-varying policies. The difference would provide a measure of the cost of simplicity or implementability. Second, the solution of this model could be compared to a socially optimal solution where the leader optimizes joint welfare but implements constant policies. These extensions are clearly of intellectual interest. Solving the resulting games and implementing the equilibrium results remain a major challenge. More generally, the model could be extended to consider several resources or more complex hydro-geological systems. One condition for such extension is that the researcher be able to describe the dynamics of the resource stock. Likewise, the model could be extended to consider users with more divergent characteristics, for example farmers with field crops on the one hand and fruit and vegetable producers on the other hand. Finally, it would be possible to consider a central government that regulates several different resource systems at a time, being subject to a single budget constraint. It would then be possible to apply the decision making tool at a national level. However, the link between groundwater use and pollution still needs to be locally determined and input taxes must be directed towards the polluters, in order to be efficient policies. 


\section{A Appendix}

A.1 Proof of $\frac{\partial \tilde{f}}{\partial \phi}<0, \frac{\partial \tilde{f}}{\partial \tau}<0, \frac{\partial \tilde{w}}{\partial \phi}<0, \frac{\partial \tilde{w}}{\partial \tau}<0$,

Solving $\dot{D}=N \tilde{w}-r$, gives:

$$
D(t)=e^{-\rho t} D_{0}+\Theta(\tau, \phi)\left(1-e^{-\rho t}\right),
$$

where

$$
\begin{gathered}
\rho=\frac{-N K C}{p\left(A^{2}-M K\right)}>0 \\
\Theta(\tau, \phi)=-\frac{A(L+\tau-p E)+K(Z-p B+\phi)}{K C}-\frac{r}{\rho} .
\end{gathered}
$$

Therefore:

$$
\begin{aligned}
& \frac{\partial D}{\partial \tau}=-\frac{A}{K C}\left[1-e^{-\rho t}\right]<0, \\
& \frac{\partial D}{\partial \phi}=-\frac{1}{C}\left[1-e^{-\rho t}\right]<0,
\end{aligned}
$$

and:

$$
\begin{aligned}
\frac{\partial \tilde{f}}{\partial \phi} & =-\frac{1}{p\left(A^{2}-M K\right)} A\left[-1-C \frac{\partial D}{\partial \phi}\right]=-\frac{1}{p\left(A^{2}-M K\right)} A\left[-e^{-\rho t}\right]<0 \\
\frac{\partial \tilde{f}}{\partial \tau} & =-\frac{1}{p\left(A^{2}-M K\right)}\left[-A C \frac{\partial D}{\partial \tau}-M\right]=-\frac{1}{p\left(A^{2}-M K\right)}\left(\frac{A^{2}}{K}-M\right)<0 \\
\frac{\partial \tilde{w}}{\partial \phi} & =-\frac{1}{p\left(A^{2}-M K\right)}\left[-K-K C \frac{\partial D}{\partial \phi}\right]=-\frac{1}{p\left(A^{2}-M K\right)} K\left[-e^{-\rho t}\right]<0 \\
\frac{\partial \tilde{w}}{\partial \tau} & =-\frac{1}{p\left(A^{2}-M K\right)}\left[-A-K C \frac{\partial D}{\partial \tau}\right]=-\frac{1}{p\left(A^{2}-M K\right)} A\left[-e^{-\rho t}\right]<0
\end{aligned}
$$

as

$$
-\frac{1}{p\left(A^{2}-M K\right)}>0
$$

A.2 Proof of $\frac{\partial D}{\partial \phi}<0, \frac{\partial D}{\partial \tau}<0, \frac{\partial Q}{\partial \phi}>0, \frac{\partial Q}{\partial \tau}>0$

Remember from proof (A.1) that

$$
\begin{aligned}
& \frac{\partial D}{\partial \tau}=-\frac{A}{K C}\left[1-e^{-\rho t}\right]<0 \\
& \frac{\partial D}{\partial \phi}=-\frac{1}{C}\left[1-e^{-\rho t}\right]<0 .
\end{aligned}
$$

Also, remember that independently of wheather $\sigma$ a function of $t$ or a constant

$$
Q(t, \phi, \tau)=Q_{0}-\int_{0}^{t}[\delta N \tilde{f}(t) D(t)-\zeta \sigma(t)] d t .
$$

the following relation is true:

$$
\operatorname{sign}\left(\frac{\partial D(t, \phi)}{\partial \phi}\right)=\operatorname{sign}\left(\frac{\partial \Theta(\phi)}{\partial \phi}\right)=\operatorname{sign}(-1)<0 .
$$


Author-produced version of the article published in Environmental Science \& Policy, 2014, N44, p. 201-214. The original publication is available at http://www.sciencedirect.com/science/article/pii/S1462901114001580 Doi: 10.1016/j.envsci.2014.08.002

Consequently:

$$
\frac{\partial Q}{\partial \phi}=-\delta N \int_{0}^{t} \frac{d}{\partial \phi}[f \tilde{(s)} D(s)] d s=-\delta N \int_{0}^{t}\left[\frac{\partial f \tilde{(s)}}{\partial \phi} D(s)+\tilde{f} \frac{\partial D}{\partial \phi}\right] d s>0
$$

as

$$
\frac{\partial \tilde{f}}{\partial \phi}<0, D(s)>0, \tilde{f}>0, \frac{\partial D}{\partial \phi}<0 .
$$

Likewise:

$$
\frac{\partial Q}{\partial \tau}=-\delta N \int_{0}^{t} \frac{d}{\partial \tau}[f \tilde{f}(s) D(s)] d s=-\delta N \int_{0}^{t}\left[\frac{\partial f \tilde{f} s)}{\partial \tau} D(s)+\tilde{f} \frac{\partial D}{\partial \tau}\right] d s>0
$$

as

$$
\frac{\partial \tilde{f}}{\partial \tau}<0, D(s)>0, \tilde{f}>0, \frac{\partial D}{\partial \tau}<0 .
$$




\section{References}

[1] Burness, H.S., Brill, T. C., 2001. The role for policy in common pool groundwater use. Resource and Energy Economics, 23(1), 19-40.

[2] Centre d'Analyse Stratégique, 2011. Les aides publiques dommageables à la biodiversité, La Documentation Francaise (ed.), 412p.

[3] Conseil d'État, 2010. L'eau et son droit. Rapport annuel du Conseil d'État, La Documentation Francaise (ed.), 584p.

[4] Cummings, R. G., 1971. Optimum Exploitation of Groundwater Reserves with Saltwater Intrusion. Water Resources Research 7 (6), 1415-1424.

[5] De Frutos Cachorro, J., Erdlenbruch, K., Tidball, M., 2014. Optimal adaptation strategies to face shocks on groundwater resources. Journal of Economic Dynamics and Control, 40, 134-153.

[6] Dinar, A., Xepapadeas, A., 1998. Regulating water quantity and quality in irrigated agriculture. Journal of Environmental Management 54, 273-289.

[7] Dockner,E.J., Jorgensen, S., Ngo Van Long, Sorger, G., 2000. Differential Games in Economics and Management Science, Cambridge University Press, 350p.

[8] Esteban, E., Albiac, J. 2011. Groundwater and ecosystem damages: Questionning the Gisser-Sanchez effect. Ecological Economics, 2062-2069.

[9] Gisser, M., Sanchez, D.A., 1980. Competition versus optimal control in groundwater pumping. Water Resources Research 31, 638-642.

[10] Knapp, K.C., Baerenklau, K.A., 2006. Ground Water Quantity and Quality Management: Agricultural Production and Aquifer Salinization over Long Time Scales. Journal of Agricultural and Resource Economics 31(3),616-641.

[11] Knapp, K.C., Schwabe, K.A., 2008. Spatial Dynamics of Water and Nitrogen Management in Irrigated Agriculture. American Journal of Agricultural Economics 90(2),524-539.

[12] Koundouri, P., 2004. Current Issues in the economics of groundwater resource management. Journal of Economic Surveys 18 (5), 703-740.

[13] Krawczyck, J.B., Zaccour, G., 1996. Pollution management through levies and subsidies, in: LJ. Vlacici et al. (Eds.), Modelling and Control of National and Regional Economies, an Imprint of Elsevier Science, Pergamon, 1996, 241-246.

[14] Larson, D.M., Helfand, G.E., House, B.W. 1996. Second-Best Tax Policies to Reduce Nonpoint Source Pollution. American Journal of Agricultural Economics 78, 1108-1117.

[15] G. Martín-Herrán, Taboubi, S., Zaccour, G., 2005. A Time-Consistent Open-Loop Stackelberg Equilibrium of Shelf-space Allocation. Automatica 41(6), 971-982.

[16] Moreaux, M., Reynaud, A., 2006. Urban freshwater needs and spatial cost externalities for coastal aquifers: A theoretical approach. Regional Science and Urban Economics 36, $163-186$.

[17] Provencher, B., Burt, O., 1993. The Externalities Associated with the Common Property Exploitation of Groundwater. Journal of Environmental Economics and Management 24, $139-158$. 
Author-produced version of the article published in Environmental Science \& Policy, 2014, N44, p. 201-214. The original publication is available at http://www.sciencedirect.com/science/article/pii/S1462901114001580 Doi: 10.1016/j.envsci.2014.08.002

[18] Roseta Palma, C., 2002. Groundwater Management When Water Quality Is Endogenous. Journal of Environmental Economics and Management 44, 93-105.

[19] Roseta Palma, C., 2003. Joint Quantity/Quality Management of Groundwater. Environmental and Resource Economics 26, 89-106.

[20] Sainteny, G., 2012. Plaidoyer pour l'écofiscalité, Buchet Chastel, Paris, 272p.

[21] Tsur, Y., Zemel, A., 2004. Endangered aquifers: Groundwater management under threats of catastrophic events. Water Resources Research 40, 1-10.

[22] Xepapadeas, A., 1992, Environmental Policy Design and Dynamic Nonpoint-Source Pollution. Journal of Environmental Economics and Management 23, 22-39.

[23] Yadav, S. N., 1997. Dynamic Optimization of Nitrogen Use When Groundwater Contamination Is Internalized at the Standard in the Long Run. American Journal of Agricultural Economics 79, 931-945.

[24] Zeitouni, N., Dinar, A., 1997. Mitigating Negative Water Quality and Quality Externalities by Joint Management of Adjacent Aquifers. Environmental and Resource Economics 9, 1-20. 